Tohoku J. Exp. Med., 2005, 207, 73-79

\title{
A Survey of Restaurant Smoking Restrictions in a Japanese City
}

\author{
KaZuhiko Kotani, Yoneatsu Osaki, ${ }^{1}$ Youichi Kurozawa and TaKujI Kishimoto ${ }^{1}$ \\ Division of Health Administration and Promotion, ${ }^{1}$ Division of Preventive and \\ Environmental Medicine, Faculty of Medicine, Tottori University, Yonago, Japan
}

\begin{abstract}
Kotani, K., Osaki, Y., Kurozawa, Y. and Kishimoto, T. A Survey of Restaurant Smoking Restrictions in a Japanese City. Tohoku J. Exp. Med., 2005, 207 (1), 73-79 Japan has been behind the times in terms of promoting smoking control. The health-promotion law, which included the aim of preventing environmental tobacco smoke (ETS) in public places, was newly introduced in Japan in 2003. The community-based survey on the present state of restaurant smoking restrictions and restaurant owners' concern of smoking is important as it is a reflection of the community's desire to prevent ETS. Data on the smoking restrictions in 163 restaurants in Yonago, one Japanese community, and the owners' smoking-related awareness were collected just one month after the law was enacted. This study revealed that only $6(3.6 \%)$ restaurants were under sufficient conditions: 3 with totally smoke-free and 3 with complete non-smoking sections. The styles (e.g., Western-, Japanese- and Chinese-styles) and kinds of restaurants (e.g., family restaurants and tearooms) were not related to the state of smoking restrictions. Rates of smokers were relatively high among owners, and smoking owners significantly provided insufficient smoking restrictions. $26.4 \%$ of owners knew about the new law. However, there were no restaurants that started their smoking restrictions due to the law. Owners' knowledge of the law did not correlate with smoking restrictions. The owners especially feared the negative effects on business due to smoking restrictions. These survey findings suggested little protection from ETS in a sample of restaurants and a large gap in restaurant smoking restrictions compared to other countries. More widespread adoption of the health-promotion law in restaurants is an issue. —— second hand smoke; passive smoking; owner; health promotion; descriptive epidemiology

(C) 2005 Tohoku University Medical Press
\end{abstract}

Japan has been behind the times in promoting smoking control. In 1966, the percentage of individuals who smoked occasionally or everyday reached $83.7 \%$ of adult Japanese males (aged 20 years and older) and $18.0 \%$ of adult Japanese females (Wada and Fukui 1994; Honjo and Kawachi 2000). This had decreased to $57.5 \%$ and $14.2 \%$, respectively in 1996, and decreased gradually, particularly in males (Wada and Fukui 1994; Honjo and Kawachi 2000). More recently, 46.9\% of adult males and $13.2 \%$ of adult females have been smokers in 2004 (JT News Release 2004). However, these figures for Japanese males are still higher than those of other developed countries

Received February 14, 2005; revision accepted for publication June 24, 2005.

Correspondence: Kazuhiko Kotani, M.D., Ph.D., Division of Health Administration and Promotion, Faculty of

Medicine, Tottori University, 86 Nishi-cho, Yonago 683-8503, Japan.

e-mail: kakotani@grape.med.tottori-u.ac.jp 
(Honjo and Kawachi 2000). Smoking control policy has not proceeded smoothly in Japan because of the lack of leadership by the health ministry coupled with a lack of social and political support (Sato 1999).

The harmful effects of environmental tobacco smoke (ETS) on health, such as cancer, cardiovascular and respiratory diseases (Hirayama 1981, 1984, 1990; Woodward and Laugesen 2001; Williams and Sandler 2001; Neuberger and Field 2003; Ambrose and Barua 2004), have become well-known in Japan's medical community, while socially they are not yet widely understood. Restaurants are representative sources of likely exposure to ETS for food service staff and patrons (Siegel 1993; Kottke et al. 2001). It has been reported that ETS levels in restaurants were approximately 1.6 to 2.0 times higher than in office workplaces and 1.5 times higher than in residences with at least one smoker (Siegel 1993). The amount of restaurant smoking restrictions in the community can be a sign of the growth of community knowledge, attitudes and practices in relation to ETS (Ross et al. 1993; Schofield et al. 1993). Globally, many governments and communities have enacted legislation and/or ordinances requiring restaurants to be smoke-free, and these policies have shown great effectiveness towards the reduction of ETS (Sciacca and Eckrem 1993; Bartosch and Pope 2002; Lam et al. 2002; Miller et al. 2002; Skeer and Siegel 2003). In Japan, however, restaurants can choose whether or not to be smoke-free, resulting in the continued presence of ETS. There are as yet no community-based reports on the restaurant smoking restrictions in Japan.

As of May 1, 2003, the health-promotion law, which includes the aim of preventing ETS in public places, was introduced for the first time in Japan. This new health-promotion law is nationwide, and prior to this there have been no other smoking-related laws in this country. Promotion of the law has been through media such as television, radio and print as well as public health advocacy. The law simply requires restaurants to encourage the reduction of smoking. It is not known whether the law, without any penal regula- tions, is communicated in restaurants or whether it affects the restaurant smoking restrictions. This study describes the actual state of restaurant smoking restrictions in relation to owners' smoking-related awareness, immediately after enacting the health-promotion law in one Japanese city, as a representative sample of Japanese communities.

\section{Subjects ANd Methods}

A cross-sectional study was conducted to estimate the provisions of the restaurant smoking restrictions in the Yonago area, just one month after the introduction of the new health-promotion law. The survey period was less than one week. The Yonago area is a city located in the southwestern part of the main island of Japan, with a population of approximately 135,000 residents. Yonago City has had no specific relationship to smoking restrictions and its smoking status did not differ from any other regions in Japan. There were 2,560 registered restaurants in the Yonago area (Data were supplied by the public health center of Yonago in 2003). We went to 163 restaurants advertised in town magazines (CAN Co. Ltd. 1999), which are most read among such kinds of magazines in this area, and investigated the status of smoking restrictions in a one-time observation of at least $20 \mathrm{~min}$ utes and through the restaurant owner's free comments. All surveyed restaurants had at least one table. We defined "totally non-smoking" as not allowing smoking at all in a restaurant, and defined "completely non-smoking" as setting aside a separate space using a partition in a restaurant. Taking the effective ETS control into account (Lambert et al. 1993; Repace 2004), we considered restaurants such as "totally" and "completely" nonsmoking as sufficient conditions. The types of restaurants such as Western-style, Japanese-style, Chinese-style and any combined style were enrolled; restaurants with bars were excluded from the present study. Also, among them, family restaurants and tearooms were especially selected as a restaurant type which adolescents are more likely to drop in, from the viewpoint of adolescent smoking problems (Ogawa et al. 1988; Kawabata et al. 1991; Osaki and Minowa 1993; Wada and Fukui 1994; Osaki and Minowa 1996).

We examined whether the owners in surveyed restaurants were smokers or non-smokers. Each owner was then interviewed with the question; "Do you know about the health-promotion law that aims to prevent ETS in public spaces such as restaurants?". We examined the relationship between the restaurant smoking restrictions 
and the owners' knowledge of the law.

The statistical analysis was done by chi-square analysis or Fisher exact probability test. Differences were considered significant at $p<0.05$. All data were treated anonymously, according to the national ethical guideline for epidemiological research in 2002.

\section{RESUlts}

The response rate to the present study in restaurants and the owners was $100 \%$. There were only 6 restaurants with sufficient conditions regarding smoking restrictions (Table 1). Three $(1.8 \%)$ restaurants were totally smoke-free and 3 $(1.8 \%)$ provided complete non-smoking sections. The other restaurants were classified as under insufficient conditions: 5 (3.1\%) had non-smoking times during each day, 17 (10.4\%) had ventilated tables available for non-smokers and $6(3.7 \%)$ set aside a separate seating section specifically for children and pregnant women. Among 5 restaurants with non-smoking times, 4 restaurants reserved times between 11:00 a.m. and 2:00 p.m. and one did between 10:30 a.m. and 2:30 p.m. The remaining 129 restaurants did not have smoking restrictions.

As shown in Table 1, the type of restaurant was insignificantly related to smoking restrictions, although Japanese-style restaurants seemed to have few restrictions (in a comparison of the distributed numbers of each restaurant type between the group under sufficient conditions vs. the group with insufficient conditions).

We found 4 family restaurants among all the surveyed restaurants, and 3 family restaurants among them had ventilated tables (Table 2). There were 23 tearooms, and among them only one tearoom that was totally non-smoking, 5 tearooms with ventilated tables and 2 tearooms with separate seats for children and pregnant women. One family restaurant and 15 tearooms did not have any restrictions. Among all the restaurants with ventilated tables, the percentage of family restaurants and tearooms seemed to be relatively high. However, family restaurants and tearooms themselves were statistically insignificantly associated with smoking restrictions (in a comparison of the distributed numbers of both family restaurants and tearooms to the numbers of other kinds of restaurants between the group with sufficient conditions vs. the group with insufficient conditions).

Overall, $97(59.5 \%)$ restaurant owners were smokers (Table 3). The owners of restaurants under sufficient conditions were all non-smokers.

TABLE 1. The smoking restriction status of surveyed restaurants

\begin{tabular}{lcc}
\hline \multicolumn{1}{c}{ Categories of smoking restrictions } & Numbers & Type of restaurants $^{*}$ \\
\hline $\begin{array}{l}\text { Sufficient conditions } \\
\text { 100\% smoke-free }\end{array}$ & $3(1.8 \%)$ & $2 / 1 / 0 / 0$ \\
$\quad$ With complete non-smoking sections & $3(1.8 \%)$ & $3 / 0 / 0 / 0$ \\
Insufficient conditions & $5(3.1 \%)$ & $2 / 2 / 1 / 0$ \\
$\quad$ With non-smoking times during each day & $17(10.4 \%)$ & $12 / 3 / 0 / 2$ \\
With ventilated tables for non-smokers & $6(3.7 \%)$ & $4 / 2 / 0 / 0$ \\
With separate seats specifically for & & $60 / 52 / 13 / 4$ \\
children/pregnant women & $129(79.2 \%)$ & \\
Without any restrictions & & \\
\hline
\end{tabular}

Parentheses included numbers corresponding to each category divided by all surveyed numbers. ${ }^{*}$ Respective numbers of Western-style/Japanese-style/Chinese-style/any combined style of the two or three were shown. When the numbers of each restaurant type were compared between the group under sufficient conditions (with 100\% smoke-free plus complete non-smoking sections) and the group under insufficient conditions, using chi-square test, the type of restaurants was not significantly related to smoking restrictions. 
TABLE 2. The smoking restriction status in both family restaurants and tearooms

\begin{tabular}{lc}
\hline \multicolumn{1}{c}{ Categories of smoking restrictions } & Numbers \\
\hline Sufficient conditions & $1(33.3 \%)$ \\
$100 \%$ smoke-free & $0(0.0 \%)$ \\
With complete non-smoking sections & \\
Insufficient conditions & $0(0.0 \%)$ \\
With non-smoking times during each day & $8(47.1 \%)$ \\
With ventilated tables for non-smokers & $2(33.3 \%)$ \\
With separate seats specifically for children/pregnant women & $16(12.4 \%)$ \\
Without any restrictions & \\
\hline
\end{tabular}

Parentheses included numbers corresponding to family restaurants (total number, 4) plus tearooms (total number, 23) divided by all the restaurant numbers in each category of smoking restrictions. When the numbers of family restaurants plus tearooms were compared between the group under sufficient conditions and the group under insufficient conditions, using Fisher exact probability test, family restaurants and tearooms themselves were not significantly related to the categories of smoking restrictions.

TABLE 3. The smoking status among surveyed restaurant owners

\begin{tabular}{lc}
\multicolumn{1}{c}{ Categories of smoking restrictions } & Non-smoker numbers \\
\hline Sufficient conditions & $3(100.0 \%)$ \\
$100 \%$ smoke-free & $3(100.0 \%)$ \\
With complete non-smoking sections & $2(40.0 \%)$ \\
Insufficient conditions & $7(41.2 \%)$ \\
With non-smoking times during each day & $5(83.3 \%)$ \\
With ventilated tables for non-smokers & $46(35.7 \%)$ \\
With separate seats specifically for children/pregnant women & \\
Without any restrictions &
\end{tabular}

Parentheses included corresponding numbers divided by all the owner numbers in each category of smoking restrictions. When the numbers of smoker (or non-smoker) were compared between the group under sufficient conditions and the group under insufficient conditions, using Fisher exact probability test, smoking owners were significantly related to insufficiency of smoking restrictions $(p<0.05)$.

Smoking owners were significantly correlated with insufficiency of smoking restrictions (in a comparison of the numbers of smokers between the group under sufficient conditions and the group under insufficient conditions). Fourty three (26.4\%) restaurant owners knew about the new health-promotion law (Table 4). Interestingly, no owners of restaurants under sufficient conditions knew the new law. There were no restaurants that started their smoking restrictions after the law was enacted. Owners' knowledge of the healthpromotion law was not significantly related to the categories of smoking restrictions (in a comparison of the numbers of owners who knew the health-promotion law between the group under sufficient conditions and the group under insufficient conditions). All owners who knew the law had gained information about the law from mass media such as newspapers and television programs. 
TABLE 4. The knowledge levels of the health-promotion law among surveyed restaurant owners

\begin{tabular}{lr}
\hline \multicolumn{1}{c}{ Categories of smoking restrictions } & Numbers \\
\hline Sufficient conditions & \\
100\% smoke-free & $0(0.0 \%)$ \\
With complete non-smoking sections & $0(0.0 \%)$ \\
Insufficient conditions & \\
With non-smoking times during each day & $3(60.0 \%)$ \\
With ventilated tables for non-smokers & $5(29.4 \%)$ \\
With separate seats specifically for children/pregnant women & $2(33.3 \%)$ \\
Without any restrictions & $33(25.6 \%)$ \\
\hline
\end{tabular}

Parentheses included corresponding numbers divided by all the owner numbers in each category of smoking restrictions. When the numbers of owners knowing the health-promotion law were compared between the group under sufficient conditions and the group under insufficient conditions, using Fisher exact probability test, knowing of the health-promotion law was not significantly related to the categories of smoking restrictions.

Restaurant owners' comments on regulating smoke in restaurants were mainly as follows: 1) smoke-free restaurants would decrease the enjoyment of customers/patrons, and thus restaurant business could decline (by 37 owners). 2) in general, restaurants did not have the money to spend on new separation of non-smoking spaces and the set-up of ventilation systems (by 21 owners). 3) smoking is a personal choice (by 9 owners).

\section{Discussion}

This study described few provisions for smoking restrictions in restaurants in one Japanese city, soon after the introduction of the health-promotion law. Our results from direct inspection of restaurants that put an advertisement in influential magazines seemed significant, even though this study included a small-sample size and a limitation of no measures of biomarkers to quantify the environmental exposure to smoke. Legislation and ordinances requiring restaurant smoking restrictions have been reported in many countries (Sciacca and Eckrem 1993; Bartosch and Pope 2002; Lam et al. 2002; Miller et al. 2002; Skeer and Siegel 2003; McElvaney 2004). For example, as of July 1, 2004, there are 187 municipalities with local laws and 9 states with state laws in effect that require $100 \%$ smoke-free restaurants in the United States (American Nonsmokers' Rights
Foundation 2004). More recently, smoking has been banned in restaurants throughout European countries such as Italy, Ireland and Norway (Smokefreeworld 2005).

The percentage of restaurant smoking restrictions in our survey was closely compatible with that of restaurants surveyed about 10 years ago in Australia (Schofield et al. 1993). Since the surveyed restaurants included in popular magazines generally seemed to have a higher awareness of the social trends related to current ETS controls, the actual percentage among all restaurants in this area might be lower. These findings suggested a large gap in the perception and implementation of public ETS controls between countries.

The state of smoking restrictions was similar between the types of restaurants. Also, particular kinds of restaurants such as family restaurants and tearooms which adolescents can more frequently drop in did not provide more sufficient smoking restrictions. This might reflect the fact that the public attitude to smoking prevention for adolescents is still not positive.

Among all restaurant owners, a lack of widespread knowledge of the health-promotion law was observed. The owners' knowledge of the law did not correlate with smoking restrictions in restaurants. Overall smoking rates of surveyed own- 
ers seemed relatively higher than the general trend (JT News Release 2004). It will be a future issue whether more widespread knowledge of the law and owners who quite smoking produce more smoking restrictions in restaurants.

The main reason for a low compliance towards the health-promotion law in restaurants was the owners' fears of the economic effects on restaurant business. The owners' opinions on smoking regulations were similar regardless of countries and the effect on restaurant revenues has been anticipated as one of the major causes of fear among restaurant owners before the implementation of new smoking restrictions (Ross et al. 1993). However, there have been a growing number of reports contradicting such opinions. There has been evidence that the smoke-free policies have not affected community-wide restaurant business and have even shown increased sales (Sciacca and Eckrem 1993; Bartosch and Pope 1996, 1999; Glantz and Smith 1997; Sciacca and Ratliff 1998; Hyland and Cummings 1999; Chapman et al. 2001; Wakefield et al. 2002).

Customers were more supportive than owners in thinking that smoke-free spaces should be provided (Schofield et al. 1993; Biener and Siegel 1997; Kottke et al. 2001; Lam et al. 2002; Miller et al. 2002). In Japan, the increasing numbers of restaurants with smoking restrictions will be desired among customers (Sato 1999). The legislative change has been adhered to by both owners and customers (Miller et al. 2002). In fact, in our survey, the positive effects on the business of some restaurants under sufficient smoking restrictions before the health-promotion law had been already realized. Thus, the fear of adverse economic consequences and a loss of customers by newly restrictive smoking policies are not thought to be necessary in this surveyed area. For now, each restaurant should show information about the non-smoking or smoking restrictions at the front of the establishment.

Furthermore, one of the owners' main comments on smoking restrictions was to do with the cost of providing non-smoking spaces and installing ventilation systems. These comments were not persuasive because of the following reasons.
There is the opinion that the cost of implementing smoking restrictions can in fact be inexpensive (Miller et al. 2002). Additionally, in general nonsmoking and smoking sections in a restaurant can not completely protect someone from smoke exposure (Lambert et al. 1993) and the elimination of this health risk through increased ventilation alone is not possible (Repace 2004).

Any action regarding smoking restrictions is of little practical value unless many people understand it, as documented by the Florida Clean Indoor Air Acts (Vincent et al. 1994). At present, people in the surveyed area remain unprotected from ETS in restaurants. More public demand for tobacco control, education by public health practitioners, legal action and reinforcement of campaigns on the health-promotion law will be required to make Japanese community restaurants smoke-free. Having no penal regulations in the health-promotion law may be a problem, and selfimplemented control on ETS in each restaurant could lead to a future tendency similar to the present state. If the law without penalties accomplishes little, more aggressive methods may be needed.

\section{Acknowledgments}

International Health Students' Circle including Satoshi Inoue contributed to this survey.

\section{References}

Ambrose, J.A. \& Barua, R.S. (2004) The pathophysiology of cigarette smoking and cardiovascular disease: an update. $J$. Am. Coll. Cardiol., 43, 1731-1737.

American Nonsmokers' Rights Foundation (2004) URL: http://www.no-smoking.org.

Bartosch, W.J. \& Pope, G.C. (1999) The economic effect of smoke-free restaurant policies on restaurant business in Massachusetts. J. Public Health Manag. Pract., 5, 53-62.

Bartosch, W.J. \& Pope, G.C. (2002) Economic effect of restaurant smoking restrictions on restaurant business in Massachusetts, 1992 to 1998. Tob. Control, 11, Suppl. 2, ii38ii 42 .

Biener, L. \& Siegel, M. (1997) Behavior intentions of the public after bans on smoking in restaurants and bars. Am. J. Public Health, 87, 2042-2044.

CAN Co. Ltd. (1999) Gourmet-guide in San-in area "Wink", edited by CAN Co. Ltd., Shimane. (in Japanese)

Chapman, S., Borland, R. \& Lal, A. (2001) Has the ban on smoking in New South Wales restaurants worked? A comparison of restaurants in Sydney and Melbourne. Med. J. Aust., 174, 512-515.

Glantz, S.A. \& Smith, L.R.A. (1997) The effect of ordinances 
requiring smoke-free restaurants and bars on revenues: a follow-up. Am. J. Public Health, 87, 1687-1693.

Hirayama, T. (1981) Non-smoking wives of heavy smokers have a higher risk of lung cancer: a study from Japan. Br. Med. J., 282, 183-185.

Hirayama, T. (1984) Cancer mortality in nonsmoking women with smoking husbands based on a large-scale cohort study in Japan. Prev. Med., 13, 680-690.

Hirayama, T. (1990) Passive smoking. N. Z. Med. J., 103, 54.

Honjo, K. \& Kawachi, I. (2000) Effects of market liberalisation on smoking in Japan. Tob. Control, 9, 193-200.

Hyland, A. \& Cummings, K.M. (1999) Restaurateur reports of the economic impact of the New York City Smoke-Free Air Act. J. Public Health Manag. Pract., 5, 37-42.

JT News Release. (2000) URL: http://www.jti.co.jp/News/04/ NR-no21/no21.html

Kawabata, T., Maruya, N., Nakamura, M., Oshima, A., Hiyama, T., Minagawa, K., Nishioka, N., Mochizuki, Y., Okajima, Y., Ichimura, K., Takahashi, H., Watanabe, M., Nozu, Y., Iwai, K., Okada, K. \& Takahashi, M. (1991) Smoking and alcohol drinking behavior among Japanese adolescents-results from "Japan Know Your Body Study". Nippon Koshu Eisei Zasshi, 38, 885-899. (in Japanese with English abstract)

Kottke, T.E., Aase, L.A., Brandel, C.L., Brekke, M.J., Brekke, L.N., DeBoer, S.W., Hayes, S.N., Hoffman, R.S., Menzel, P.A. \& Thomas, R.J. (2001) Attitudes of Olmsted County, Minnesota, residents about tobacco smoke in restaurants and bars. Mayo Clin. Proc., 76, 134-137.

Lam, T.H., Janghorbani, M., Hedley, A.J., Ho, S.Y., McGhee, S.M. \& Chan, B. (2002) Public opinion on smoke-free policies in restaurants and predicted effect on patronage in Hong Kong. Tob. Control, 11, 195-200.

Lambert, W.E., Samet, J.M. \& Spengler, J.D. (1993) Environmental tobacco smoke concentrations in no-smoking and smoking sections of restaurants. Am. J. Public Health, 83, 1339-1341.

McElvaney, N.G. (2004) Smoking ban-made in Ireland, for home use and for export. N. Engl. J. Med., 350, 2231-2233.

Miller, C., Wakefield, M., Kriven, S. \& Hyland, A. (2002) Evaluation of smoke-free dining in South Australia: support and compliance among the community and restaurateurs. Aust. N. Z. J. Public Health, 26, 38-44.

Neuberger, J.S. \& Field, R.W. (2003) Occupation and lung cancer in nonsmokers. Rev. Environ. Health, 18, 251-267.

Ogawa, H., Tominaga, S., Gellert, G. \& Aoki, K. (1988) Smoking among junior high school students in Nagoya, Japan. Int. J. Epidemiol., 17, 814-820.

Osaki, Y. \& Minowa, M. (1993) National survey of smoking prevalence among school students in Japan. Nippon Koshu Eisei Zasshi, 40, 39-47. (in Japanese with English abstract)

Osaki, Y. \& Minowa, M. (1996) Cigarette smoking among junior and senior high school students in Japan. J. Adolesc. Health, 18, 59-65.

Repace, J. (2004) Flying the smoky skies: secondhand smoke exposure of flight attendants. Tob. Control, 13, Suppl. 1, i8-i19.

Ross, M. H., De Beer, M. \& Algu, K. (1993) Awareness and perceptions of restaurateurs about proposed smoking restrictions in Johannesburg restaurants. J. R. Soc. Health, 113, 8-11.

Sato, H. (1999) Policy and politics of smoking control in Japan. Soc. Sci. Med., 49, 581-600.

Schofield, M.J., Considine, R., Boyle, C.A. \& Sanson-Fisher, R. (1993) Smoking control in restaurants: the effectiveness of self-regulation in Australia. Am. J. Public Health, 83, 1284-1288.

Sciacca, J.P. \& Eckrem, M. (1993) Effects of a city ordinance regulating smoking in restaurants. J. Community Health, 18, 175-182.

Sciacca, J.P. \& Ratliff, M.I. (1998) Prohibiting smoking in restaurants: effects on restaurant sales. Am. J. Health Promot., 12, 176-184.

Siegel, M. (1993) Involuntary smoking in the restaurant workplace. A review of employee exposure and health effects. JAMA, 270, 490-493.

Skeer, M. \& Siegel, M. (2003) The descriptive epidemiology of local restaurant smoking regulations in Massachusetts: an analysis of the protection of restaurant customers and workers. Tob. Control, 12, 221-226.

Smokefreeworld (2005) URL: http://www.smokefreeworld. com/

Vincent, A.L., Bradham, D., Hoecherl, S. \& McTague, D. (1994) BRFSS-based survey of the Florida public on restaurant smoking. J. Fla. Med. Assoc., 81, 171-173.

Wada, K. \& Fukui, S. (1994) Prevalence of tobacco smoking among junior high school students in Japan and background life style of smokers. Addiction, 89, 331-343.

Wakefield, M., Siahpush, M., Scollo, M., Lal, A., Hyland, A., McCaul, K. \& Miller, C. (2002) The effect of a smoke-free law on restaurant business in South Australia. Aust. N. Z. J. Public Health, 26, 375-382.

Williams, M.D. \& Sandler, A.B. (2001) The epidemiology of lung cancer. Cancer Treat. Res., 105, 31-52.

Woodward, A. \& Laugesen, M. (2001) How many deaths are caused by second hand cigarette smoke? Tob. Control, 10, 383-388. 